\title{
Modelling and Comparative Performance Analysis of Special Six-phase and Conventional Synchronous Generators for Wind Farm Application
}

\author{
P. H. B. Naves ${ }^{1}$, J. C. Oliveira ${ }^{1}$, A. F. Bonelli ${ }^{1}$ and M. V. B. Mendonça ${ }^{1}$ \\ ${ }^{1}$ Faculty of Electrical Engineering \\ UFU, Federal University of Uberlandia \\ Av. Joao Naves de Avila, 2121 - Campus Santa Monica - Bloco 3N - Uberlandia (Brazil) \\ Phone/Fax number: +0055 34 3239-4733/3239-4704, e-mail: paulonaves_eng@yahoo.com.br, jcoliveira@ufu.br, \\ afbonelli@gmail.com, borgesmarcus@yahoo.com.br
}

\begin{abstract}
This paper presents a proposal for the mathematical modelling and computational analysis of special six-phase synchronous generators as required by variable wind farm application. The strategy uses time domain techniques so as to highlight the transient, dynamic and steady state operational conditions. Having completed the representation and the computational implementation of these special machines, the model is inserted into a simplified wind complex. Objectifying the establishment of comparisons between the sixphase and conventional three-phase generator performance, general aspects such as: electrical quantities wave form, improvement of the harmonic distortion, better performance of the damper windings, among others, are focused in the study. The advantages properties associated with the use of the special machine are fully considered throughout this article.
\end{abstract}

\section{Key words}

Harmonic distortion, modelling, six-phase generator, synchronous machine, wind farm.

\section{Introduction}

Six-phase synchronous machines have been studied for many years. In the late 1920's it was reported that these devices were used for a specific application where a phase shifting of $60^{\circ}$ was required between two threephase supply arrangements [1], [2], [3]. Pursuing the goal of applying these generators in systems containing rectifiers, the technique of building up special generators has been found attractive in the sense of increasing the number of pulses [4], [5], [6], [7]. Although the mentioned references deal with the focused special machine, it must be stressed they are not strictly tight to wind system application.

The subject of using six-phase generators with a $30^{\circ}$ displacement between the two internal three-phase systems, as necessary for wind systems, is still a topic with a great lack of information as far as publications are concerned. In this particular case, only in [8] was found a direct correlation between the machine in focus and its use in wind farms. This paper, however, deals with a permanent magnetic synchronous generator and the wind network is extremely simplified in its representation. Although the lack of information about this type of machine it is worldwide known that the use of six-phase generators has been pointed out as a modern tendency for new plants involving the exploitation of wind energy.

Harmonics associated with the operation of 6 pulse rectifier and lower DC voltage are the main disadvantages that arises the idea of applying the special six-phase arrangement for wind systems. As matter of fact, the 12 pulse rectifier properties are quite attractive as far as harmonic current reduction, DC voltage level and content in magnitude and order and that DC voltage level are concerned. Having in mind these initial advantages and others that will be pointed out in this article, the thesis that wind farms should be constituted of six-phase synchronous machines is growing in importance.

Therefore, the main goal of this work is the modelling and performance studies associated to the special machine under discussion. The model to be described is based on mathematical representation of the device throughout time domain representation and its computational implementation into an appropriate program. Then, a variety of performance analysis is carried out to highlight the special machine behaviour and its advantages in comparison to the classical threephase generator.

\section{Physical Arrangement and Modelling of the Generator}

The six-phase synchronous generator is built in such a way to provide two sets of three-phase windings (with displaced coils of $120^{\circ}$ between). These two arrangements are displaced by $30^{\circ}$. In this way, the internal structure presents two sets of three-phase windings, identified as $a b c$ and $x y z$, respectively. Fig. 1 
evidences the constructive principle of the machine under analysis. The figure also shows the reference axes $a b c$, $x y z$ and the well known $d q$ reference.

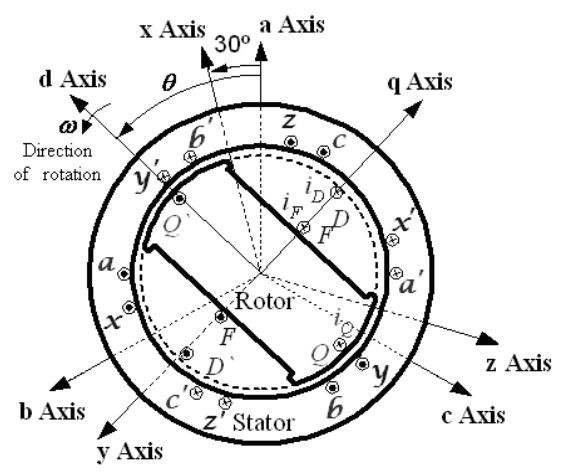

Fig. 1. Physical arrangement for the six-phase generator.

To obtain the representative expressions for the machine, the first step consists in finding the equations for the inductances. These must take into account the magnetic coupling between each pair of windings and that they dependent on the rotor position for salient pole machines. This strategy is fully based on [9].

Thus, expression (1), generically, defines the behavior of the self inductance of a single phase of the stator:

$$
L_{i i}=\left(L_{s 1}+L_{s 2}\right)+L_{m} \cdot \cos 2\left(\theta+\alpha_{i}\right)
$$

Seeing that:

$$
\begin{aligned}
L_{i i}- & \text { self inductance of each phase of the stator, } \\
& \text { where subindex } i \text { must assume the values of } \\
& a, b, c, x, y \text { and } z \text {, for } i=i \text {; }
\end{aligned}
$$

The mutual inductance between any two phases of the stator can be represented by the following expression:

$$
L_{i k}=-M_{s}-L_{m} \cdot \cos \left[2\left(\theta+\alpha_{i k}\right)\right]
$$

Where:

$L_{i k} \quad$ - mutual inductance between two phases of the stator, where subindex $i i$ must assume: $a, b, c$, $x, y$ and $z$, for $i \neq k$, and $L_{i k}=L_{k i}$;

$M_{s}$ - average value of the mutual inductance;

$L_{m}$ - amplitude of the variable term of the mutual inductance;

$\theta \quad$ - angle that defines the rotor position;

$\alpha_{i k}$ - angle where the mutual inductance is maximum in relation to the reference.
The general expression that describes the mutual inductance between a phase of the stator and the rotor is:

$$
L_{i k}=M_{k} \cdot \cos \left(\theta+\alpha_{i k}\right)
$$

Seeing that:

$$
\begin{aligned}
L_{i k}- & \text { mutual inductance between a generic phase of } \\
& \text { the stator and with any coil of the rotor, } \\
& \text { where the subindex } i k \text { must assume } i=a, b, c, \\
& x, y \text { and } z \text {, and } k=F, D \text { and } Q \text {, and } L_{i k=} L_{k i} ; \\
M_{k}- & \text { amplitude of the variable term of the mutual } \\
& \text { inductance; } \\
\theta \quad- & \text { angle that defines the rotor position; } \\
\alpha_{i k}- & \text { angle between the axis of the phase in } \\
& \text { analysis and the reference. }
\end{aligned}
$$

With regard to the self inductance of the rotor, it is given by equation (4).

$$
L_{i i}=L_{i 1}+L_{i 2}
$$

Where:

$$
\begin{aligned}
L_{i i}- & \text { self inductance of a given rotor coil, where } \\
& \text { subindex } i i \text { assumes: } F, D \text { and } Q \text {, for } i=i ; \\
L_{i 1}- & \text { coil self inductance; } \\
L_{i 2}- & \text { coil leakage inductance. }
\end{aligned}
$$

The general expression for the mutual inductance between the pertaining rotor coils can be written as:

$$
L_{i k}=L_{i 1}
$$

Where:

$$
\begin{aligned}
& L_{i k}-\text { mutual inductance between the circuits under } \\
& \text { analysis, where the subindex } i k \text { assumes: } F, D \\
& \text { and } Q \text {, for } i \neq k \text {. }
\end{aligned}
$$

From the knowledge of inductances that describe the operation of the machine, it becomes feasible to obtain expressions to correlate the magnetic flux and their respective currents that are present in windings of the generator. These equations are, in a general form, given by expression (6).

$$
[\lambda]=[L] \cdot[i]
$$

Where:

$$
\begin{aligned}
& {[\lambda]-\text { vector of the concatenated flux; }} \\
& {[L]-\text { matrix of the machine's inductances; }} \\
& {[i]-\text { array of currents in the windings of the }} \\
& \text { machine. }
\end{aligned}
$$

In function of the previous definitions it is possible, from (6), to obtain the equations for the concatenated flux for all the windings of the six-phase synchronous machine. This produces equation (7). 


$\left[\begin{array}{l}\lambda_{a} \\ \lambda_{b} \\ \lambda_{c} \\ \lambda_{x} \\ \lambda_{y} \\ \lambda_{z} \\ \lambda_{F} \\ \lambda_{D} \\ \lambda_{Q}\end{array}\right]=\left[\begin{array}{lllllllll}L_{a a} & L_{a b} & L_{a c} & L_{a x} & L_{a y} & L_{a z} & L_{a F} & L_{a D} & L_{a Q} \\ L_{b a} & L_{b b} & L_{b c} & L_{b x} & L_{b y} & L_{b z} & L_{b F} & L_{b D} & L_{b Q} \\ L_{c a} & L_{c b} & L_{c c} & L_{c x} & L_{c y} & L_{c z} & L_{c F} & L_{c D} & L_{c Q} \\ L_{x a} & L_{x b} & L_{x c} & L_{x x} & L_{x y} & L_{x z} & L_{x F} & L_{x D} & L_{x Q} \\ L_{y a} & L_{y b} & L_{y c} & L_{y x} & L_{y y} & L_{y z} & L_{y F} & L_{y D} & L_{y Q} \\ L_{z a} & L_{z b} & L_{z c} & L_{z x} & L_{z y} & L_{z z} & L_{z F} & L_{z D} & L_{z Q} \\ L_{F a} & L_{F b} & L_{F c} & L_{F x} & L_{F y} & L_{F z} & L_{F F} & L_{F D} & L_{F Q} \\ L_{D a} & L_{D b} & L_{D c} & L_{D x} & L_{D y} & L_{D z} & L_{D F} & L_{D D} & L_{D Q} \\ L_{Q a} & L_{Q b} & L_{Q c} & L_{Q x} & L_{Q y} & L_{Q z} & L_{Q F} & L_{Q D} & L_{Q Q}\end{array}\right] \bullet\left[\begin{array}{c}i_{a} \\ i_{b} \\ i_{c} \\ i_{x} \\ i_{y} \\ i_{z} \\ i_{F} \\ i_{D} \\ i_{Q}\end{array}\right](7)$

The electromagnetic torque can be obtained from the principle of energy conservation. The result of the application of this fundament law leads to:

$$
T_{e}=\frac{p}{2} \sum_{i} \sum_{k} i_{i} i_{k} \frac{d L_{i k}}{d \theta}
$$

Seeing that:

$T_{e}$ - electromagnetic torque developed by the generator;

$p \quad$ - number of poles of the generator;

$i$ - currents in the windings of the generator, where $i$ and $k$ assumes: $a, b, c, x, y, z, F, D, Q$.

$\frac{d L_{i k}}{d \theta}=L_{i k} \quad-\quad \begin{aligned} & \text { derivatives of the inductances of the } \\ & \text { windings of the machine, for } i \text { and } k\end{aligned}$ assuming: $a, b, c, x, y, z, F, D, Q$.

The dynamics of the movement of the synchronous machine can be given by:

$$
J \frac{d^{2} \theta}{d^{2} t}=T_{T}-T_{e}
$$

Where:

$$
\begin{aligned}
& T_{T}-\text { primary drive torque (wind turbine); } \\
& T_{e}-\text { electromagnetic torque; } \\
& J-\text { inertia moment. }
\end{aligned}
$$

The equations of the voltages associated with the terminals of the distinct windings can be obtained from basic principles of electrical circuits. These lead to expressions of the type:

$$
v=e-r \cdot i
$$

Where:

$$
\begin{aligned}
& v \quad-\text { terminal voltage in the winding; } \\
& r \quad-\text { resistance of the winding; } \\
& i \quad-\text { winding current; } \\
& e \quad-\text { electromotriz force produced in the winding } \\
& \text { and given by: } \\
& e=-\frac{d(L i)}{d t}=-\frac{d \lambda}{d t}
\end{aligned}
$$

Substituting (11) in (10):

$$
v=-r \cdot i-\frac{d \lambda}{d t}
$$

Therefore, to obtain the voltage equations, (12) must be applied to each winding in the machine under consideration.

\section{Characterization of the Wind Complex}

Fig. 2 illustrates the constituent parts of a full wind complex. The figure assumes the presence of a six-phase generator, in the terms argued in this work. The complex includes: the equivalent model of the wind incident in the wind turbine; a unit for rectification / inversion; a coupling transformer, and the point of coupling of the wind farm with the AC network connection.

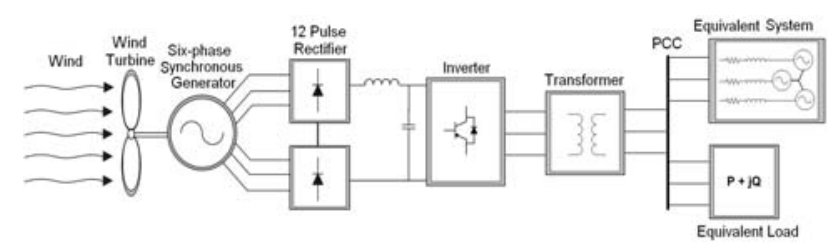

Fig. 2. Complete wind complex.

Although the recognition that the complete system has the indicated topology, for greater simplicity of the analysis of results, the focus of the subsequent studies were directed to a more simplified arrangement, as shown in Figures 3 and 4. As it is evidenced, both figures omitted the downstream parts of the rectifier, which were modeled by an equivalent load. This measure aimed, above all, to provide a better strategy for the characterization of the wave forms to be evaluated, thus avoiding the influences of switching effects associated with the operation of inverters. In addition, it is shown that the adopted configuration related to the special generator supplies a 12 pulse rectifier meanwhile the classical generator is feeding a 6 pulse unit.

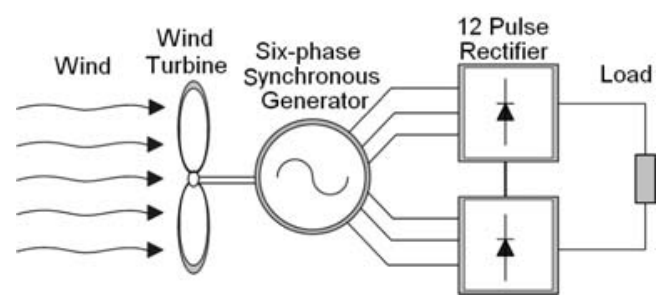

Fig. 3. Simplified system with six-phase generator and 12 pulse rectifier.

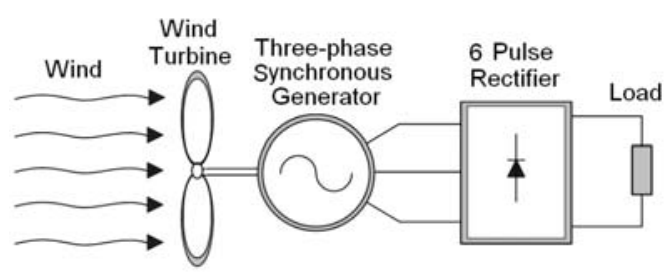

Fig. 4. Simplified system with three-phase generator and 6 pulse rectifier. 


\section{Computational Comparative Analysis}

The main objective of the computational studies is to establish comparative terms between the operational characteristics between the two machines, with special attention to the wave forms and the harmonic distortion. For both schemes, the following operational variables are focused: three-phase voltages at the generator's terminals; three-phase currents supplying the rectifiers; magnetic flux in the machine; electromagnetic torque; field current; damper winding current; rectifier output voltage and current.

Regarding the primary source of energy, the wind, both systems operated with identical conditions, without any turbulence. Among the characteristic data for the sixphase generator, no reference was found that would allow the extraction of the parameters necessary for its modeling. Therefore it was decided to employ equivalent parameters to conventional generators with compatible power rating. Table I indicates the parameters used for the generators being studied.

TABLE I. Generator parameters.

\begin{tabular}{l|c|c}
\hline \multicolumn{1}{c|}{ Description } & Parameter & Value \\
\hline Rated power - (MVA) & Snom & 1 \\
\hline Rated voltage - (kV) & Vnom & 0.6 \\
\hline $\begin{array}{l}\text { Direct axis synchronous reactance - } \\
\text { (pu) }\end{array}$ & Xd & 1,225 \\
\hline $\begin{array}{l}\text { Quadrature axis synchronous } \\
\text { reactance - (pu) }\end{array}$ & Xq & 1,133 \\
\hline Stator leakage inductance - (pu) & Xl & 0,15 \\
\hline Direct axis transient reactance - (pu) & X’d & 0,248 \\
\hline $\begin{array}{l}\text { Direct axis subtransient reactance - } \\
\text { (pu) }\end{array}$ & X”d & 0,184 \\
\hline $\begin{array}{l}\text { Quadrature axis subtransient } \\
\text { reactance - (pu) }\end{array}$ & X”q & 0,212 \\
\hline Stator resistance - (pu) & Rs & 0,013 \\
\hline $\begin{array}{l}\text { Direct axis transient open circuit } \\
\text { time constant - (s) }\end{array}$ & T’d0 & 0.108 \\
\hline $\begin{array}{l}\text { Direct axis subtransient open circuit } \\
\text { time constant - (s) }\end{array}$ & T’d0 & 0,044 \\
\hline $\begin{array}{l}\text { Direct axis subtransient open circuit } \\
\text { time constant - (s) }\end{array}$ & T”q0 & 0,0017 \\
\hline Moment of inertia - (s) & Inercia & 50000 \\
\hline Excitation no load current - (A) & I_rotor & 200 \\
\hline Rotational speed - (rad/s) & $\omega$ & 3,65 \\
\hline Frequency - (Hz) & f & 17 \\
\hline Pole pairs & 60 \\
\hline
\end{tabular}

For comparative analysis of the voltages and currents at the generators output, the adopted procedure was to establish a correlation between the quantities related to the $a b c$ phases of the three-phase generator and the corresponding quantities associated to the $a b c$ phases of the six-phase generator. Investigations involving the $x y z$ windings were not made only the $30^{\circ}$ phase-shift was noticed between the corresponding results.

Fig. 5 shows details of the output voltages at the terminals of each of the studied generators. It is observed that only the voltages between the phases $a$ and $b$, for both machines, are inserted into the graph. The value of the total harmonic distortion associated to the line voltage, for the classical generator, was found to be $8.4 \%$. Concerning the special machine, the THD achieved $5.6 \%$.

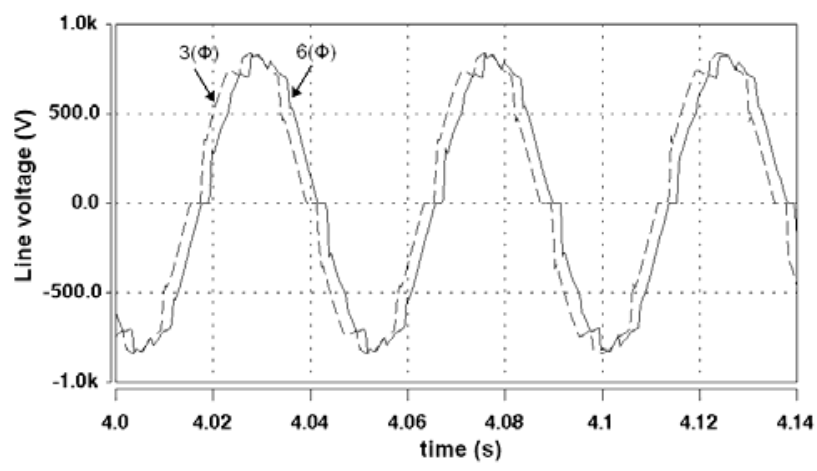

Fig. 5. Line voltages at the output of the two generators.

Fig. 6 illustrates the line currents supplied by each of the machines focused in the study. It can be seen that each winding forming the six-phase generator produces a current of $50 \%$ of the value of the other generator. This is a direct consequence of the fact that the special machine splits the total current in two windings. The harmonic contents are almost the same for both wave forms and they are in accordance with typical 6 pulse rectifiers.

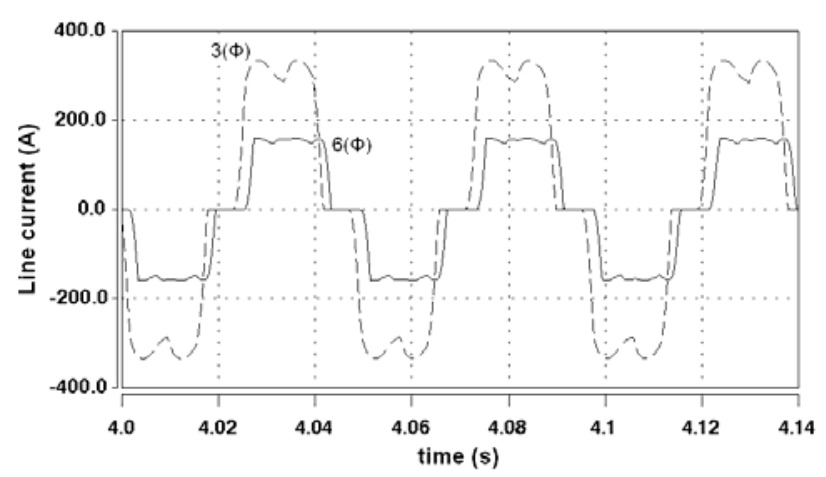

Fig. 6. Line currents supplied by the two generators.

The magnetic flux associated with each phase is shown in Fig. 7. The wave forms are quite similar for both generators and do not present appreciable distortion.

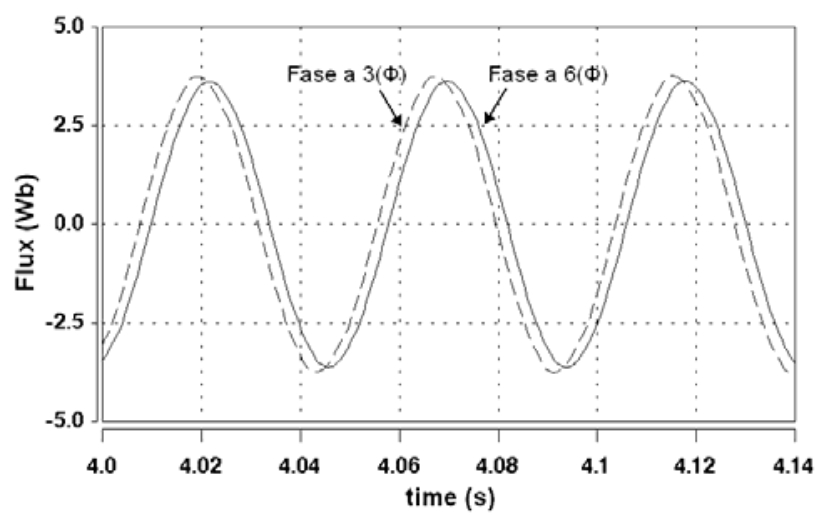

Fig. 7. Phase $a$ magnetic flux for both generators. 
Fig. 8 illustrates the electromagnetic torque produced by each generator. The reduction obtained in the pulsation of the developed torque by the use of the six-phase configuration is evident. The value of the total harmonic distortion was also significantly decreased. It is evidenced that the total distortion for the six-phase machine is about $40 \%$ of that found for the conventional machine. The elimination of the 6th harmonic component was decisive for this reduction.

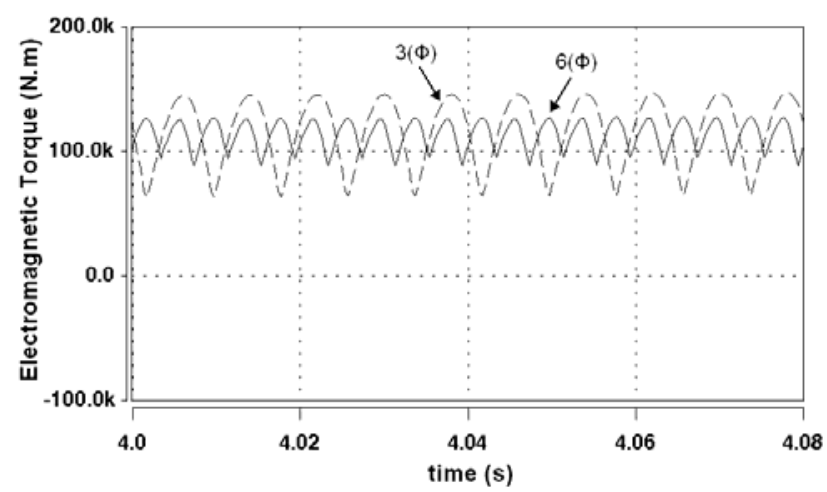

Fig. 8. Electromagnetic torque produced by the three-phase and six-phase generators.

Comparing the wave forms of the field currents for the machines, there are also large reductions in fluctuations when the six-phase generation is employed. Fig. 9 highlights this fact and leads to the conclusion that the total harmonic distortion is reduced to about $40 \%$ of the value found for the conventional three-phase machine.

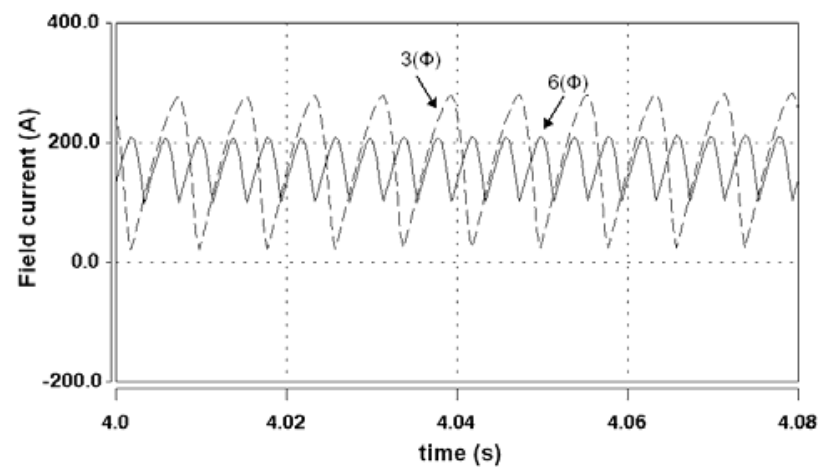

Fig. 9. Field current for both generators.

Added to the positive properties previously observed, it is also noted that the employment of the six-phase generation brings expressive gains to the reduction of currents which occurs in the damper windings. In this particular case, Fig. 10 provides a ready comparison between the situations found in each generator. In ideal operational conditions, this current should be null, however, due to the non sinusoidal characteristics involved in the process, such a situation does not occur. Moreover, the six-phase arrangement gives a reduction of about $60 \%$ in the effective value of this current diminishing the problems associated with improper circulation in this type of application.

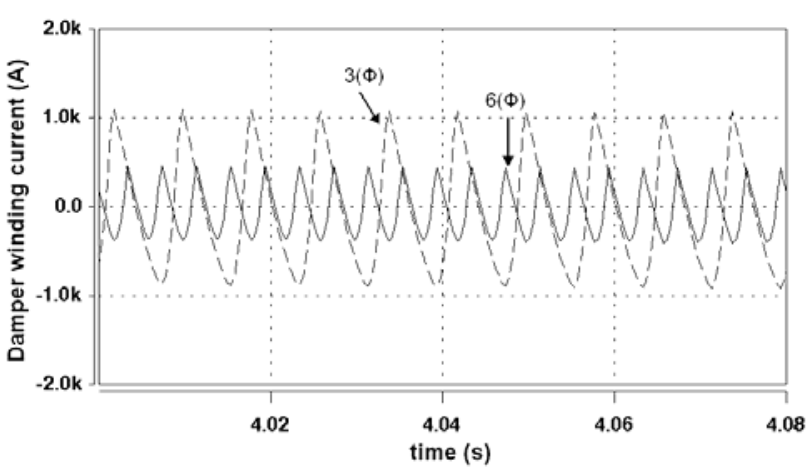

Fig. 10. Damper windings currents for both generators.

Another important feature associated with the use of the six-phase arrangement in comparison to traditional one is the DC voltage wave form. In accordance with Fig. 11, the first option is capable of producing a double value of voltage. In addition, it is also recognized that the use of the 12 pulse rectifier leads to a DC voltage with a lower level of distortion.

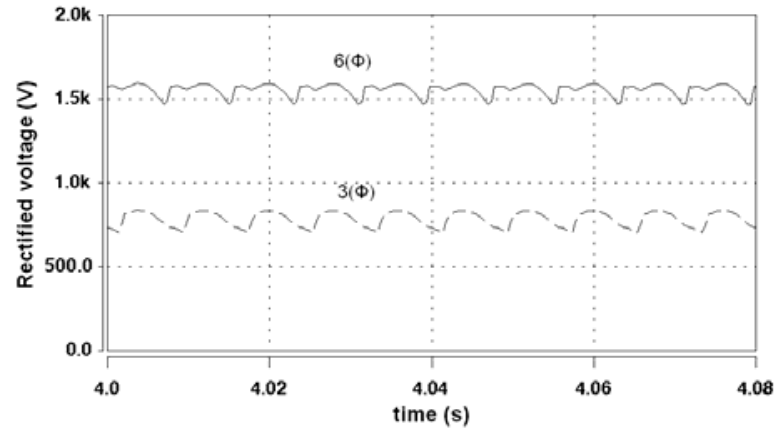

Fig. 11. Rectified voltages for both systems.

The direct current obtained at the rectifier output also gains improvements with the use of the six-phase system, as evidenced in Fig. 12. The total distortion of the current is reduced by $60 \%$. Regarding the current level, it is $50 \%$ of the value associated with that of the conventional generator, however, as was already observed, the DC voltage is doubled for the six-phase machine, this implies the power is still the same for both machines.

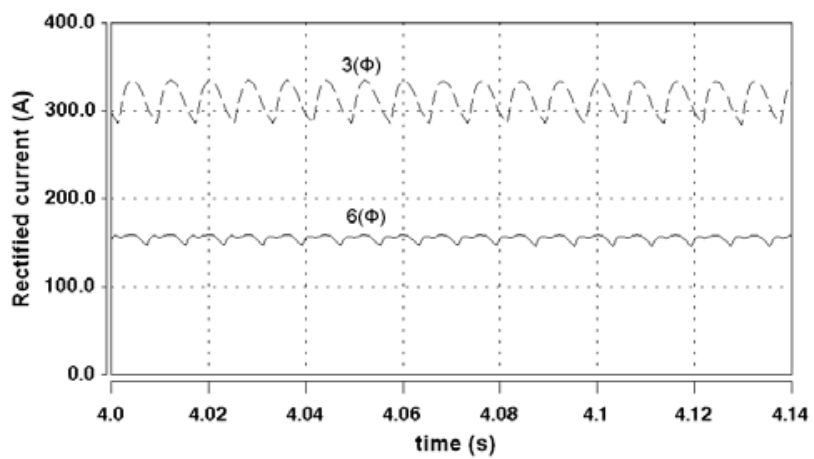

Fig. 12. Rectified currents for both systems.

Table II synthesizes and compare the main numerical values obtained for the two investigated configurations and clearly manifests the superiority of the performance 
of the electric complex that makes use of the special sixphase synchronous generation.

TABLE II. Comparative synthesis between the results.

\begin{tabular}{l|c|c|c|c}
\hline \multirow{2}{*}{$\begin{array}{l}\text { Operational } \\
\text { Variables }\end{array}$} & \multicolumn{2}{|c|}{$\begin{array}{c}\text { Six-phase } \\
\text { Generator }\end{array}$} & \multicolumn{2}{c}{$\begin{array}{c}\text { Three-phase } \\
\text { Generator }\end{array}$} \\
\cline { 2 - 5 } & $\begin{array}{c}R S \\
\text { value }\end{array}$ & $\begin{array}{c}\text { Total } \\
\text { Harmonic } \\
\text { distortion } \\
{[\%]}\end{array}$ & $\begin{array}{c}R M S \\
\text { value }\end{array}$ & $\begin{array}{c}\text { Total } \\
\text { Harmonic } \\
\text { Distortion } \\
{[\%]}\end{array}$ \\
\hline $\begin{array}{l}\text { Line voltage } \\
\text { (V) }\end{array}$ & 582 & 5.6 & 586 & 8.4 \\
\hline $\begin{array}{l}\text { Line current } \\
\text { (A) }\end{array}$ & 125 & 25 & 256 & 25 \\
\hline $\begin{array}{l}\text { Magnetic } \\
\text { flux (Wb) }\end{array}$ & 2.6 & 0.62 & 2.7 & 1.1 \\
\hline $\begin{array}{l}\text { Torque } \\
\text { (N.m) }\end{array}$ & 91502 & 13.5 & 91651 & 33 \\
\hline $\begin{array}{l}\text { Field current } \\
\text { (A) }\end{array}$ & 183 & 28 & 186 & 68 \\
\hline $\begin{array}{l}\text { Direct axis } \\
\text { damper } \\
\text { current (A) }\end{array}$ & 275 & 28 & 643 & 35 \\
\hline $\begin{array}{l}\text { Rectified } \\
\text { voltage (V) }\end{array}$ & 1564 & 3.1 & 784 & 7.7 \\
\hline $\begin{array}{l}\text { Rectified } \\
\text { current (A) }\end{array}$ & 155 & 2.9 & 313 & 7.3 \\
\hline
\end{tabular}

Still aiming to provide clearer comparisons between the results associated with the harmonic distortions, Fig. 13 correlates the harmonic distortions and evidences the gains arising from the employment of the special machine.

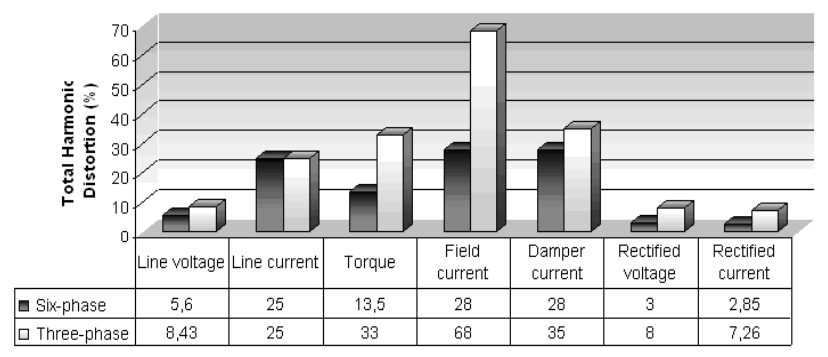

Fig. 13. Comparative graph of the total harmonic distortions.

\section{Conclusions}

This paper has presented a mathematical basis for the modeling of special six-phase synchronous generators, following the current trend of wind farms. The representations culminated in a set of expressions that use techniques in time domain. This fact is of great relevance for studies of the wave forms associated with the process in question. After the respective computational implementation of the model, there followed a set of studies for the evaluation of a simplified complex through which it was possible to correlate the operation of the special generator to that of the conventional threephase machine.
The reduction of harmonic components is caused, mainly, by the deliberate displacement of $30^{\circ}$ of the two sets of the special machine windings and their connection with the 12 pulse rectifier. Besides the improvements in the harmonic spectrum, it became clear other ameliorations not less important, such as: RMS reduction of the line current at the generator output and at the rectifier output, large reduction of the current at the damper windings, mechanical torque oscillatory improvements, voltage increase at the rectifier output, amongst other advantages were found. Thus, the results underscore the operational advantages of the six-phase unit and highlight some properties that justify the technology proposed in this article.

\section{References}

[1] R.F. Schiferl, C.M. Ong, "Six Phase Synchronous Machine with AC and DC Stator Connections, Part I: Equivalent Circuit Representation and Steady-State Analysis”, IEEE Transactions on Power Apparatus and Systems, October 1983, pp 2685 - 2693.

[2] E. F. Fuchs, and L. T. Rosenberg, "Analysis of an Alternator with Two Displaced Stator Windings”, IEEE Transactions on Power Apparatus and Systems, Vol. 93, No. 6, 1974, pp. 1776-1786.

[3] H. J. Hegner, P. C. Krause, O. Wasynczuk, E. Water, S. Pekarek, "Parameter measurement of a six-phase synchronous machine for simulation of machine/converter systems”, Energy Conversion Engineering Conference, 1996.IECEC96. Proceedings of the 31st Intersociety, October 1996, pp $1792-1797$ vol.3.

[4] J. Jatskevich, S. D. Pekarek, "Six-phase synchronous generator-rectifier parametric average value modeling considering operational modes”, HAIT Journal of Science and Engineering B, Volume 2, Issues 3-4, pp 365-385 Copyright 2005 Holon Academic Institute of Technology.

[5] K. Zhang, H. M. Kojabadi, P. Z. Wang, L. Chang, "Modeling of a Converter-Connected Six-Phase Permnanent Magnet Synchronous Generator”, Power Electronics and Drives Systems, 2005. PEDS 2005. International Conference on Volume 2, 28-01 November, 2005 pp:1096 - 1100.

[6] J. Jatskevich, S. D. Pekarek, "Six-phase synchronous generator-rectifier parametric average value modeling considering operational modes", HAIT Journal of Science and Engineering B, Volume 2, Issues 3-4, pp. 365-385 Copyright 2005 Holon Academic Institute of Technology.

[7] S.D. Sudhoff, "Analysis and average-value modeling of a dual line-commutated converter - 6-phase synchronous machine systems", IEEE Transactions on Energy Conversion, Vol. 8, No. 3, September 1993.

[8] S. Kato, Y. Inui, M. Michihira, A. Tsuyoshi, "Low-Cost Wind Generator System with a Permanent Magnet Synchronous Generator and Diode Rectifiers", ICREPQ'06 International Conference on Renewable Energy and Power Quality, 2006.

[9] L. Martins Neto, R. G. Mendonça, R. V. R. Silva, S. C. M. Paula, "Three-Phase Induction Generator Feeding a Single- Phase Electrical Distribution System - Time Domain Mathematical Model”. Proceedings of the IEEE ACEMP 2001 - International Aegean Conference on Electrical Machines and Power Electronics, 2001, Kusadasi. 